\title{
INVESTIGATING SELECTED GASTRONOMIC TRENDS FROM DEMAND AND SUPPLY SIDE
}

\author{
Alžbeta Királ'ová ${ }^{1}$ \\ Lukáš Malec ${ }^{2}$
}

Received: November 21, 2019 / Revised: January 10, 2020 / Accepted: February 14, 2020

(C) Association of Economists and Managers of the Balkans, 2020

\begin{abstract}
The study aims to identify the role of the selected gastronomic trends in the Czech gastronomic establishments. The study highlights the key findings of quantitative and qualitative research provided with the focus on both the demand and the supply side. It is focusing on the dispute between guests' opinions and entrepreneurs' views based on few variables for gastronomic trends. Entrepreneurs' and guests' views in three Czech Regions were studied in one set with notes incorporated on possible mutual differences between them. The partial least squares variant of linear discriminant analysis (plsLDA) and partial least squares (PLS) was applied as they give a clear superiority due to both, interpretational and stability property. It was proven that the partial least squares variants lead to direct answers to questions in the studied field. Participation/organization of food festivals and slow food are positively related. The significant tasks emerge to a great extent covering differences between guests' and entrepreneurs' opinions. On the other hand, the connection of economic interest to gastronomic trends is relatively weak.
\end{abstract}

Keywords: Gastronomy, Czech Republic, Regions, Tourism, Gastronomic Establishments, Restaurants, SME, Destination, Guest, Visitor, Entrepreneur.

\section{JEL Classification L83}

This paper was presented at the Third International Scientific Conference on IT, Tourism, Economics, Management and Agriculture - ITEMA 2019 - October 24, Bratislava, Slovakia, www.itema-conference.com

Alžbeta Királ’ová

alzbeta.kiralova@ambis.cz

1 College of Regional Development and Banking Institute - AMBIS, Lindnerova575/1, 18000 Prague 8 - Libeň, Czech Republic

2 University College of Business in Prague, Spálená 76/14, 11000 Prague 1 - New Town, Czech Republic 


\section{INTRODUCTION}

Gastronomy and food tourism are factors of the regional economic growth through the development of small and medium-sized enterprises and contributes to the development of the regions (Királ'ová \& Hamarneh, 2016). In certain types of special interest tourism, food becomes a central motivation for travel (Hall \& Mitchell, 2001). Indeed, Hashimoto \& Telfer (2003) describe how food in tourism has developed from being a necessity to become an additional „tourist experience” that may enhance the overall evaluation of the travel experience. Food tourism can be a tool for the economic development of the region with high unemployment and low socioeconomic status. Specialized local traditional food and beverages create the opportunity for the development of rural tours, direct purchasing from the farms, and specialized restaurant menus (Bessiere, 1998). The main advantage of the gastronomy and food tourism is its ability to adapt and respond to the effects of phenomena such as globalization, localization, or creolization, mainly because living culture-related changes (Richards, 2002).

The growing interest and demand from destinations visitors for local products are very much rooted in the changing patterns of tourism, particularly the growth of „special interest „(Hall \& Mitchell, 2001) and „new” tourism (Poon, 1993). According to Poon (1993), new tourists are searching more for real and authentic cultural and natural experiences. As food has been recognized as an essential part of local culture and identity (Richards, 2002), trying out local food specialties may serve to enrich the overall experience of tourists seeking to learn more about a different and authentic culture. Through the growing demand for regional food, an increasing number of destinations use cuisines as their major tourism attractions (Enteleca, 2001, Karim, 2006).

Tourism is traditionally made up of small and micro enterprises and linking consumers to producers (Enteleca Research, 2001). Gastronomy is a combination of the knowledge, experience, art, and craft, which provides a healthy and pleasurable eating experience, forms part of the country's identity, and is an essential component of the Czech cultural heritage. Gastronomy is one of the most important cultural expressions of human beings. The purpose of the study is to identify the moderating effect of selected gastronomic trends on the relationship between guest intention to visit the gastronomic establishment and the product based on the selected gastronomic trends.

According to the objective of the study, the research questions are formulated as follows:

Research Question 1: What is the difference between guests' and entrepreneurs' opinions for selected gastronomic trends?

Research Question 2: What is the relationship between the selected gastronomic trends and the guests' intention to visit?

The study hypothesis is set as follow:

Hypothesis: Application of selected trends in gastronomy has a significant effect on the development of enterprises.

From the reason of near-collinearity within the sets, the partial least squares variants of standard multivariate techniques are applied in this study. The plsLDA and PLS approaches were used. Such types of techniques are marginally used in the economy even though they reveal excellent asymptotic properties and straightness of solution. The covariance is to be maximized in PLS (Wegelin, 2000) instead of correlations for a more traditional canonical analysis. A functional link between both methods is discussed by Malec (2016). The input variables are standardized due to equal significance in statistical processing methods. 


\section{DATA AND METHODS}

The data source covers three NUTS3 regions of the Czech Republic as the representative for the whole area, i.e., Praha (PHA), Středočeský (STC) and Ustecký (ULK) regions based on questionnaire survey realized in 2017. The random samples cover both the restaurant guests and entrepreneurs to reveal disputes in their opinions covering the fundamental part of the study. The survey was distributed to guests via the selected social media platform. The number of guests was 611 with shares $40.84 \%$ for Praha, 40.57\% for Středočeský Region, and 18.59\% for Ustecký Region. In total, 150 completed questionnaires were received for restaurant entrepreneurs based on known spatial proportions of individual establishments (PPM Factum, 2014). The stratified sampling based on experts' opinion was the method of choice to gather data. The Likert scale is used to examine the data using a 5-point approach from 1 - strongly disagree to 5 -strongly agree. There were revealed high skewed data for questionnaire survey outputs. For this reason, the transformations are used $y=\log (x)+1$ for sample skewness $>2$ on input variables (asks) and similarly using natural logarithm on a reversed scale for negatively skewed data.

Due to the collinearity measured via determinant of sample correlation matrices ranged below 10-25 within the individual sets, the multivariate partial least squares variants are utilized to process the data. The plsLDA and PLS are the methods of choice using the linear combinations of original variables in the form of latent variates (LVs). Used PLS technique is also abbreviated PLS-SVD and called intercorrelations analysis or canonical covariance, which, on the contrary to more common canonical correlation analysis, examines the covariance between LVs (Wegelin, 2000). Similarly, partial least squares analogy of discriminant analysis to encompass differences between the sets was applied in this study. Malec and Királová (2018) describe the considerable transformation in the case of two-set, where such approaches can be considered as an alternative to other regression techniques (Bílková, 2019). The eigenvalues express the significance of individual LVs, coefficients of linear combinations serve to investigate the relational pattern between variables, and the score is the latent variable plot. The eigenvalues are scaled using sample size. The t-tests were used to reveal the significance of the differences between entrepreneurs' and guests' sets, as well as for examining the correlation coefficients.

\section{RESULTS AND DISCUSSION}

Food is a vital part of culture and creativity, a significant element of intangible heritage, and an increasingly important attraction for tourists. Food is a shift from the „must-see” to „must experience." Experiences are linking global and local cultures, creating food narratives, co-creation by guests, and collaborative gastronomy. Products around food events, routes, trails, and new cuisines support place branding and serve as a powerful vehicle to reflect the uniqueness of a destination (Dupeyras, 2015).

Gastronomy is a combination of knowledge, experience, art, and craft, which provides a healthy and pleasurable eating experience, forms part of the country's identity, and is an essential component of the Czech cultural heritage. Czech regions have a long-lasting tradition of preparation of food and culture; however, the structure of growth regarding regional distribution in the Czech Republic is problematic. The regions that can offer food and beverages prepared and served in a typical way, followed by a unique consumption culture, can develop food tourism (Hall \& Mitchell, 2002). The relationship between food and tourism promotes policies that improve economic and social well-being and as such, enhance the regional development. Studies provided in this field confirmed that local food increases the capability of sustainable tourism, reinforces the local 
economy, supports the environmentally friendly infrastructure, and is part of the originality of a destination (Du Rand et al. 2003).

In order to find out the answer of the set research questions and in order to confirm or refute the defined hypothesis, the following gastronomic trends were selected: (1) open space kitchen, (2) slow food, (3) participation/organization of food festivals, (4) authentic traditional food offer, (5) connection between food and wine offer, (6) mobile application, (7) Wi-Fi, and (8) sustainable and ecological behavior of gastronomic establishments.

It should be noted covering input data that participation/organization of food festivals and slow food are strongly and positively related covering this area. The dispute between selected guests' and entrepreneurs' views based on few variables for gastronomic trends was studied. The tasks sound, „Which current gastronomic trends are interesting for you” opposite to „To what extent do you apply current trends in gastronomic tourism." Table 1 introduces the means (Mean) and coefficients of variation (Var) covering descriptive statistics as well as the discriminant coefficients. The most demanded from guests are the variables offer of authentic traditional food and the connection between food and wine opposite to slow food. In the case of entrepreneurs, the most important are considered mobile applications and Wi-Fi opposite to open space kitchen, participation/organization of food festivals, and slow food. The most variable in the guest view is slow food and mobile application and Wi-Fi. For the entrepreneurs, the open space kitchen is the most variable.

In the dispute between guests' and entrepreneurs' opinion, the measure of dissimilarity given by eigenvalue 4.444, is demonstrated in Table 1. All asks are significantly distant for the $p$-value $<$ 0.001 with one exception sustainable and ecological behavior of gastronomic establishments for high $p$-value $>0.2$. The most different covering the plsLDA coefficients are open space kitchen and participation in food festivals, where the guests' opinion outperforms the entrepreneurs' offer. Covering mobile applications and $\mathrm{Wi}-\mathrm{Fi}$, the entrepreneurs overestimate the demand for this service.

Table 1. Descriptive statistics and results of plsLDA for individual asks Source: Authors

\begin{tabular}{|l|c|c|c|c|c|c|c|}
\hline $\begin{array}{l}\text { Open space } \\
\text { kitchen }\end{array}$ & Slow food & $\begin{array}{c}\text { Food } \\
\text { festivals }\end{array}$ & $\begin{array}{c}\text { Authentic } \\
\text { traditional } \\
\text { food }\end{array}$ & $\begin{array}{c}\text { Food and } \\
\text { wine }\end{array}$ & $\begin{array}{c}\text { Mobile } \\
\text { application }\end{array}$ & $\begin{array}{c}\text { Ecological } \\
\text { behavior }\end{array}$ \\
\hline Guests opinion descriptive statistics \\
\hline Mean & 3.332 & 2.835 & 3.213 & 3.542 & 3.515 & 3.100 & 3.293 \\
\hline Var & 0.380 & 0.435 & 0.407 & 0.336 & 0.353 & 0.422 & 0.367 \\
\hline Entrepreneurs descriptive statistics \\
\hline Mean & 2.101 & 2.126 & 2.123 & 3.133 & 3.092 & 3.626 & 3.220 \\
\hline Var & 0.619 & 0.546 & 0.532 & 0.380 & 0.422 & 0.373 & 0.389 \\
\hline Discriminant coefficients & \multicolumn{7}{|l}{} \\
\hline LV & 0.628 & 0.362 & 0.557 & 0.209 & 0.216 & -0.269 & 0.038 \\
\hline
\end{tabular}

The sets are variable covering individual regions (see Fig. 1). Ustecký Region is relatively distant in both cases due to high guest demand for current trends in gastronomy except for slow food and authentic traditional food offer, which are relatively equal between regions. In the entrepreneurs set, the slow food and authentic traditional food offer are generally overestimated from the entrepreneurs set in the Ustecký Region opposite to mobile applications and Wi-Fi, which is slightly underrated there. Vertical lines mark the location of the sets separately for visitors (V) and entrepreneurs (E). 


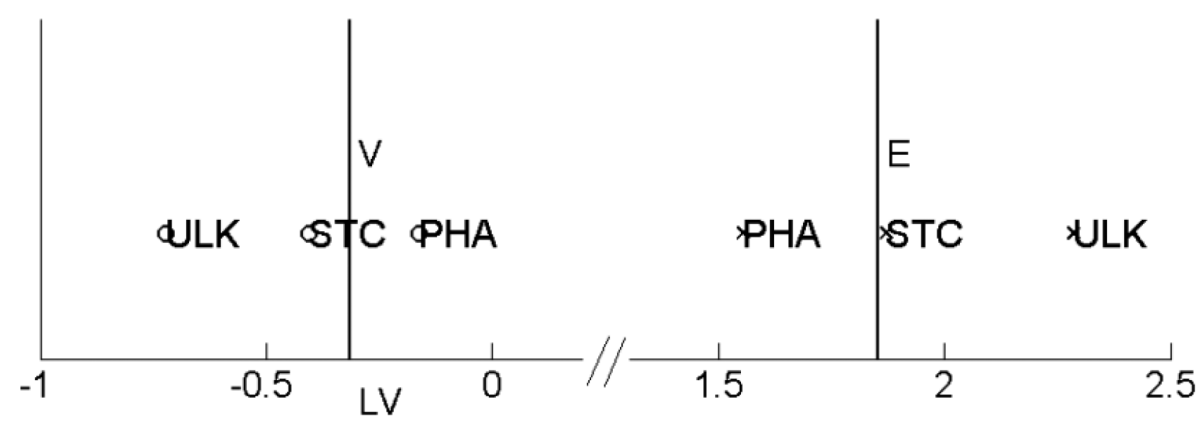

Figure 1. Position of centroids for individual regions

Source: Authors

Covering guests' side, the second area of study is economic interest asks supported by the national gastronomy using the PLS algorithm. It deals with: „Which current gastronomic trends are interesting for you" and "If the gastronomic establishments apply new trends, it will affect my behavior as follows” covering „I come more times”, „willingly pay more”, „I visit the restaurant with friends", and „I will spread the goodwill of the restaurant”.

For the first latent variable, it gathers $48.7 \%$ of the variance, while the second one $23.9 \%$ (Table 2). Here, especially authentic traditional food offer is positively related to „I visit the restaurant with friends," and „I will spread the goodwill of the restaurant.” The negative relation of sustainable and ecological behavior of gastronomic establishments to all the guests' interests can be seen. The correlations between authentic traditional food offer and „I visit the restaurant with friends" are moreover analyzed for the significance by simple t-test, where the corresponding $p$-value is 0.085 . Due to this is only the one value below 0.1, covering the pairs of variables for both sets, such relations are expected relatively weak, and we examine only the first LVs within this study.

Table 2. First PLS coefficients

Source: Authors

\begin{tabular}{|l|c|c|c|c|c|c|c|}
\hline & $\begin{array}{c}\text { Open space } \\
\text { kitchen }\end{array}$ & Slow food & $\begin{array}{c}\text { Food } \\
\text { festivals }\end{array}$ & $\begin{array}{c}\text { Authentic } \\
\text { traditional } \\
\text { food }\end{array}$ & $\begin{array}{c}\text { Food and } \\
\text { wine }\end{array}$ & $\begin{array}{c}\text { Mobile } \\
\text { application }\end{array}$ & $\begin{array}{c}\text { Ecological } \\
\text { behavior }\end{array}$ \\
\hline LV & -0.200 & 0.210 & -0.362 & 0.653 & -0.334 & 0.181 & -0.464 \\
\hline & More times & $\begin{array}{c}\text { Willingly } \\
\text { pay more }\end{array}$ & $\begin{array}{c}\text { Friends } \\
\text { visit }\end{array}$ & Good name & & & \\
\cline { 1 - 4 } LV & 0.426 & 0.276 & 0.690 & 0.517 & \multicolumn{2}{|l}{} &
\end{tabular}

\section{FUTURE RESEARCH DIRECTIONS}

In the future, the authors will concentrate on the identification of the effect of using regional and seasonal ingredients for preparing meals and dishes on the guests' intention to visit the gastronomic establishment. The trend to use local and regional ingredients refers to the distance of the place of production to the place food is eaten. Preference to eat food produced in the vicinity supports the locavorism (De Azevedo, 2015), which promotes the sale and consumption of products that are characteristic of the territory. Consuming local products is advantageous because it contributed to environmental sustainability, promotion of the region's heritage, and guarantee that the products offered are fresh. 


\section{CONCLUSION}

It was proven that the partial least squares variants behave usefully and lead to the direct answer to questions in the field of gastronomy. Participation/organization of food festivals and slow food are positively related. When covering differences between guests' opinions and entrepreneurs, the significant tasks emerge to a great extent. On the other hand, the connection of economic interest to gastronomic trends is relatively weak. Covering Research Question 1, the application of selected trends in gastronomy emerges the significantly different opinions of guests and entrepreneurs. Guests are especially interested in the offer of authentic traditional food and connection with food and wine offer opposite to slow food. The most different between both sets are open space kitchen and participation in food festivals where the guests' opinion outperforms the entrepreneurs' offer. The entrepreneurs overestimate mobile applications and Wi-Fi. In the scope of the Hypothesis, overcoming such discrepancies has a significant moderating effect on the economic behavior of gastronomy establishments and its future process.

Moreover, the regions are mutually relatively variable. Ustecký Region is distant for visitors due to high demand generally on current trends in gastronomy tourism excepting slow food and offer of authentic traditional food. There, the slow food and offer of authentic traditional food are moreover overestimated from the entrepreneurs set; this indicates that the new trends are being promoted in the Ustecký Region as a whole and, for the current time, they suppress the original directions given, for example, by traditional cuisine.

It was revealed that for current gastronomic trends, the guests' intention to visit is proven not very significantly associated with Research Question 2 and Hypothesis. Here, the offer of authentic traditional food is positively related primarily to visit a restaurant with friends. Interesting is the adverse relation of the sustainable and ecological behavior of gastronomic establishments to all the guests' interests. Nevertheless, due to the weak relationship, this would deserve a more indepth investigation covering this topic.

\section{REFERENCES}

Bessiere, J. (1998). Local development and heritage: Traditional food and cuisine as tourist attraction in rural areas. Sociologia Ruralis, 38(1), 21-33.

Bílková, D. (2019). Analysis of wages and selected indicators in OECD countries. Politická ekonomie, 67(2), 133-156.

De Azevedo, E. (2015). Food activism: The locavorism perspective. Ambiente and Sociedade, 18(3). https://dx.doi.org/10.1590/1809-4422ASOC740V1832015

Dupeyras, A. (2015). Food and the Tourism Experience. The European Commission Food Tourism Week, 28 September 2015, Milan: OECD.

Du Rand, G. E., Heath, E. \& Alberts, N., (2003). The role of local and regional food in destination marketing: A South African situation analysis. Journal of Travel \& Tourism Marketing, 14(3/4), 97 - 112.

Enteleca Research (2001). Tourist's attitudes towards regional and local food [online]. https:// tourisminsights.info/ONLINEPUB/FARMING\%20AND\%20FOOD/FOOD\%20PDFS/ tourist $\% 20$ attitutes $\% 20$ to $\% 20$ local $\% 20$ foods.pdf

Hall, C.M., \& Mitchell, R., (2002). The changing nature of the relationship between cuisine and tourism in Australia and New Zealand: From fusion cuisine to food networks. In A.-M. Hjalager \& G. Richards (Eds.). Tourism and Gastronomy (p. 188 - 206). London: Routledge. 
Hall, C. M. \& Mitchell, R. 2001. Wine and food tourism. In N. Douglas \& R. Derrett (Eds.), Special interest tourism (p. 307-329). Brisbane: John Wiley \& Sons.

Hashimoto, A. \& Telfer, D. J. (2003). Food tourism in the Niagara region: The development of a "nouvelle cuisine." In C. M. Hall, E. Sharples, R. Mitchell, B. Cambourne, \& N. Macionis (Eds.), Food tourism around the world: Development, management and markets (p. 178191). Oxford: Butterworth-Heinemann.

Karim, S. A. (2006). Culinary tourism as a destination attraction: An empirical examination of the destination's food image and information sources. PhD. thesis, Oklahoma State University.

Királ'ová, A. \& Hamarneh, I. (2016). Enhancing tourism SMEs development through food tourism in the Czech regions. In V. Klímová \& V. Žitek (Eds.), 19th International Colloquium on Regional Sciences (p. 1064-1073). Conference Proceedings, Brno: Masaryk University.

Malec, L. (2016). Some remarks on the functional relation between canonical correlation analysis and partial least squares. Journal of Statistical Computation and Simulation, 86(12), 2379-2391.

Malec, L. \& Királ'ová, A. (2018). Evaluating competencies of graduates in tourism as a prerequisite for future employability. Prague Economic Papers, 27(2) 196-214.

Poon, A. (1993). Tourism, technology and competitive strategies. Wallingford: CABI International.

PPM factum (2014). Monitoring stravovacích zařizení - prezentace hlavnich výsledki̊. Praha: PPM Factum.

Richards, G. (2002). Gastronomy: An essential ingredient in tourism production and consumption? In A. M. Hjalager, \& G. Richards (Eds.), Tourism and gastronomy (p. 3-20) London: Routledge.

Wegelin, J. A. (2000). A survey of partial least squares (PLS) methods, with emphasis on the two-block case (Technical Report No 371). Seattle: Department of Statistics, University of Washington. 